\title{
HYBRID GENETIC ALGORITHM TO THE SYNTHESIS OF OPTIMAL HEAT EXCHANGER NETWORKS
}

\author{
M. A. S. S. Ravagnani ${ }^{\mathrm{a}}$, ABSTRACT \\ A. P. Silva ${ }^{a}$, \\ and A. A. Constantino ${ }^{b}$ \\ In this paper a new systematic is proposed, interfacing Pinch Analysis and Genetic \\ Algorithms (GA). Initially the optimal $\Delta \mathrm{T}_{\min }$ is found by using a genetic algorithm. In a \\ second step, with the optimal $\Delta \mathrm{T}_{\min }$, the pinch point is obtained, and the problem is divided \\ Universidade Estadual de Maringá

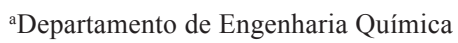

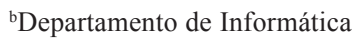 \\ Av. Colombo 5790 \\ CEP 87020-900, Maringá, Paraná, Brasil \\ ravag@deq.uem.br \\ in two regions, below and above it. The optimal HEN is obtained for each side of the \\ pinch and the final HEN is achieved. An example from the literature was solved using the \\ proposed systematic. Results show the applicability of the proposed methodology, obtaining \\ a cost value lower than those presented in the literature. \\ Keywords: Pinch Analysis, Genetic Algorithms, heat exchanger networks
}

\section{NOMENCLATURE}

$a, b, c$ cost function constants that depend on the type ofequipment used

$A_{\text {min }}$

$\mathrm{C}_{\text {capital }}$ minimum heat transfer area, $\mathrm{m}^{2}$

$C_{C U}$

$\mathrm{C}_{\text {energy }}$

$\mathrm{C}_{\text {global }}$

$C_{H U}$

$C U$

$C U_{\min }$

$f$

capital cost, \$/year

cold utility cost, $\$ / \mathrm{kW} /$ year

energy cost, \$/year

global cost, \$/year

hot utility cost, $\$ / \mathrm{kW} /$ year

cold utility consumption, $\mathrm{kW}$

cold utilities minimum demand

factor multiplicative of $\Delta \mathrm{T}_{\min }$ to relaxe the constrain

$\mathrm{h} \quad$ individual heat transfer coefficient

$H U$ hot utility consumption, $\mathrm{kW}$

$H U_{\text {min }}$ hot utilities minimum demand

$i \quad$ interest rate

$N \quad$ number of streams, including hot and cold utilities

$Q \quad$ heat exchanged

q heat

$t \quad$ plant life time, years

$T c_{i n} \quad$ inlet cold stream temperature

$T c_{\text {out }}$ outlet cold stream temperature

$T h_{\text {in }} \quad$ inlet hot stream temperature

$T c_{\text {out }} \quad$ outlet hot stream temperature

$U$ global heat transfer coefficient

$U_{\text {min }}$ minimum number of heat transfer equipment

\section{Greek symbols}

$\Delta T_{L M} \quad$ logarithm mean temperature difference

$\Delta \mathrm{T}_{\min }$ minimum approach temperature

\section{Subscripts}

$i \quad$ streams

$j \quad$ intervals

$k \quad$ equipment

\section{INTRODUCTION}

Excessive energy consumption by using hot and cold utilities influences hardly the global cost of industrial processes. For this reason, one of the designer major worries has been the reduction of utilities consumption, as well as the reduction of fixed cost in the equipment.

Most of the papers published in the area presents Pinch Analysis and Mathematical Programming, using integer linear and non-linear programming as alternatives to solve the heat exchangers network synthesis problem.

Some important published papers are Linnhoff et al. (1982), Linnhoff and Hindmarsh (1983), Linnhoff (1993), Linnhoff (1994) and Ravagnani et al. (2003), using Pinch Analysis and Papoulias and Grossmann (1983) and Floudas et al. (1996), using Mathematical Programming.

Recently, some heuristic methods of optimization have been used in heat exchanger networks synthesis.

In the present paper, a systematic procedure 
was developed, using Genetic Algorithms together with Pinch Analysis concepts, to the optimal heat exchanger network synthesis, with minimum global cost.

\section{MATERIAL AND METHODS}

Genetic Algorithms are relatively recent methods. They do not use any information of derivate, and because of this, they present good chances of escape from local minimum. Their application in practical problems generally brings to global optimal, or, at least, to solutions more satisfactory than those ones obtained by other methods.

Genetic Algorithms use a direct analogy of the evolution phenomena in nature, in such a way that each individual represents a possible solution to a given problem. The individuals are randomly determined from the search space. The 'fitness' of the solutions, which is the result of the variable that is to be optimized, is determined subsequently from the fitness function. The individual that generates the best fitness within the population has the highest chance to return in the next generation, with the opportunity to reproduce by cross over, with another individual, producing decedents with both characteristics. If a genetic algorithm is developed correctly, the population (group of possible solutions) will converge to an optimal solution for the proposed problem. The processes that have more contribution to the evolution are the crossover, based in the selection and reproduction and the mutation.

Genetic Algorithms are different from the traditional methods of search and optimization, especially because they work with a codification of the group of parameters and not with the parameters, and they use a population, and not just a point.

Besides genetic operators, it is also important to analyze the influence of some parameters in the behavior and in the performance of the genetic algorithm, to establish them according to the problem necessities and the available resources. The influence of each parameter in the algorithm performance depends on the class of problems that is being treated. Thus, the determination of an optimized group of values to these parameters will depend on a great number of experiments and tests.

The main genetic parameters are the size of the population that affects the global performance and the efficiency of the genetic algorithm, the mutation rate that avoids that a given position remains stationary in a value, or that the search becomes essentially random.

Some important papers were published in industrial applications, like Castell et al. (1998), Wang et al. (1998), Hugget et al. (1999), Yuen et al. (2000), Nougués et al. (2002), Stephan and Chase (2003) and recently, specifically in heat exchanger networks synthesis, Ravagnani et al. (2005).

Some steps compose the systematic procedure developed in this paper.

In the first step of the developed methodology, optimal DT ${ }_{\text {min }}$ is found by using a Genetic Algorithm. The function global cost is obtained by summing the annual cost of energy and the capital cost. In this stage, the heat exchangers network is not yet synthesized. In this way, the heat transfer area to be used in the cost function is the minimum possible heat transfer area, to the network to be synthesized. This area is found, after the $\mathrm{DT}_{\text {min }}$ optimization, to a group of heat and cold streams by plotting the composite curves in a diagram Temperature $\times$ Enthalpy $(\mathrm{TH})$. For each $\mathrm{DT}_{\text {min }}$ fixed, a different value for $\mathrm{A}_{\min }$ and for hot and cold utilities are found. Consequently, for the function global cost, which depends on these variables, different values will be obtained.

In a second step, pinch point is found and the problem is divided in two different regions, above and below it. Optimal heat exchanger networks are synthesized by using another Genetic Algorithm.

Finally, the optimal heat exchanger network is achieved combining both sub-networks previously synthesized.

The systematic procedure was tested with a case from the literature. Results showed the efficiency of the developed methodology during the $\mathrm{DT}_{\min }$ optimization as well as in the achievement of the optimal configuration of the heat exchanger network.

\section{PROBLEM FORMULATION}

Genetic Algorithms are based in the species natural selection and evolution, mainly considering the more apt individuals surviving. The individuals that present better adjustment (better value of the objective function) show higher probabilities of crossover and to transmit to the next generation their well succeeded genes. Nevertheless, all the individuals, apt or not, can be mutated from time to time. In this way, Genetic Algorithms are relatively recent optimization methods and no 
information about derivates are needed. In such a way, they present good chances of escaping from local optimum.

There are no guarantees about their convergence. However, when applied in practical problems, generally the global optimum is found, or, at least, for more satisfactory solutions than those one obtained by another methods.

\section{$\Delta \mathrm{T}_{\min }$ Optimization}

In this stage, Eq. (1), proposed by Towsend and Linnhoff (1984), is used:

$$
A_{\min }=\sum_{j}^{\text {intervals }} \frac{1}{\Delta T_{L M j}} \cdot\left(\sum_{i}^{\text {streams }} \frac{q_{i}}{h_{i}}\right)_{\mathrm{j}}
$$

where: $j$ represents enthalpy intervals and $i$ the processes streams, in a $\mathrm{TH}$ diagram, to the composite curves, divided in enthalpy intervals; $\Delta T_{L M}$ represents the logarithm mean temperature difference to the streams $i$ in the interval $j ; q_{i}$ and $h_{i}$ are the available or necessary heat amount and the individual convection heat transfer coefficient, respectively.

For each $\Delta \mathrm{T}_{\min }$, a different value of $A_{\min }$ is found and different hot and cold utilities demands are obtained. Consequently, the global cost function that depends on these variables will have different values.

The annual energy, capital and global cost are described in Eqs. (2), (3) and (4), respectively.

$$
\begin{aligned}
& C_{\text {Energy }}=C_{H U} \cdot H U+C_{C U} \cdot C U \\
& C_{\text {Capital }}=\left(a+b \cdot A_{\min }{ }^{c}\right) \frac{(1+i)^{t}}{t} \\
& C_{\text {Global }}=C_{\text {Energy }}+C_{\text {Capital }}
\end{aligned}
$$

where: is the hot utility cost, in $\$ / \mathrm{kW} /$ year; is the cold utility cost, in $\$ / \mathrm{kW} /$ yeas; $H U$ is the hot utility consumption, in $\mathrm{kW}$; $C U$ is the cold utility consumption, in $\mathrm{kW} ; a, b$ and $c$ are constants and depend on the equipment type used; $i$ is the interest rate; $t$ is the plant life time, in years; are given in $\$$ year.

As mentioned above, and depends on $\mathrm{DT}_{\text {min. }}$ In this way, optimal $\mathrm{DT}_{\text {min }}$ is found by minimizing Eq. (4). This minimum value represents the minimum heat exchanger network cost. This is, therefore, the objective function to be minimized in the first step of this work. The non-linear function is optimized by using a Genetic Algorithm.

The genetic operators used in this stage are initialization, aptitude calculus, crossover, mutation and selection. The two parents that will generate a child are chosen by the roulette method of selection. Each parent individual is represented in the roulette proportionally to its aptitude. In this way, a greater portion in the roulette is given to the individuals with high aptitude. To the individuals with low aptitude a small portion in the roulette is given. Finally, the roulette is rotated and the parents are drawn.

Mathematically, the probability of selection of an individual is calculated as the ratio between the individual aptitude and the sum of all the aptitudes. Based in this value, it can be determined the draw range favorable to that individual. In such a way, any random number drawn between 0 and 1 can be associated to one individual.

During the mutation step not all children are selected. To know if a child will mutate or note, a random number is generated to each child. If this number is less or equal to the mutation rate, this child will mutate. If not, it will not mutate.

\section{Heat Exchanger Network Synthesis}

The heat exchanger network synthesis task consists in finding matches between hot and cold streams, hot streams and cold utilities and cold streams and hot utilities. The set of all equipment used in these matches is the heat exchanger network.

However, finding viable combinations without violating the Second Law of Thermodynamics and being also economically viable is not an easy task. As the number of streams is increased, the number of probable combinations is also increased. In this way, heat exchanger network synthesis is not viable without computers.

The global cost of a heat exchanger network, as shown in Eq. (5), depends on the hot and utilities cost and on the capital cost, related to the heat exchanger area. The minor utilities consumption will be achieved if respected minimum hot and cold utilities demands, found by using Pinch Analysis concepts, to a determined $\mathrm{DT}_{\min }$. 
Minimum capital cost will be achieved by finding the streams combination that uses heat exchanger equipment (heat exchangers, coolers and heaters) with the smallest heat exchange area. The optimal heat exchanger network presents the minor global cost. Some constraints must be satisfied.

These constraints are shown below. Heat must be transferred from a hot to a cold stream. Hot stream must have temperatures grater than cold stream, as shown in Eq. (6). The minimum number of heat transfer equipment must be found, in each sub-network, as in Eq. (9).

Subject to:

$$
\begin{aligned}
& \left\{\begin{array}{l}
\left(T h_{\text {in }}\right)_{k}>\left(T c_{\text {out }}\right)_{k} \\
\left(T h_{\text {out }}\right)_{k}>\left(T c_{\text {in }}\right)_{k}
\end{array}\right. \\
& \mathrm{k}=1, \ldots \text {, number of equipment } \\
& \begin{array}{l}
\left\{\begin{array}{l}
\left|\left(T h_{\text {in }}\right)_{k}-\left(T c_{\text {out }}\right)_{k}\right| \geq f \cdot \Delta T_{\min } \\
\left|\left(T h_{\text {out }}\right)_{k}-\left(T c_{\text {in }}\right)_{k}\right| \geq f \cdot \Delta T_{\min }
\end{array}\right. \\
\mathrm{k}=1, \ldots, \text { number of equipment }
\end{array} \\
& \left\{\begin{array}{l}
H U \leq H U_{\min } \\
C U \leq C U_{\min }
\end{array}\right. \\
& U_{\text {min }}=N-1
\end{aligned}
$$

where: $C_{H U}, C_{C U}, H U, C U, i, t, a, b$ and $c$ are known; $k$ represents equipment; $A$ is the heat exchanger area for each equipment; $T h_{\text {in }}$ and $T c_{\text {out }}$ are inlet and outlet hot stream temperatures; $T c_{\text {in }}$ and $T c_{\text {out }}$ are inlet and outlet cold stream temperatures; $f$ is a factor multiplicative of $\Delta \mathrm{T}_{\text {min }}$ to relaxe the constrain; $H U_{\min }$ and $C U_{\min }$ are hot and cold utilities minimum demand; $U_{\min }$ is the minimum number of heat transfer equipment; $N$ is the number of streams, including hot and cold utilities.

Heat transfer area is found by Eq. (10) for each equipment present in the network. In this equation, $Q$ is the heat exchanged, $U$ is the global heat transfer coefficient and $\Delta T_{L M}$ is the logarithm mean temperature difference.

$$
A \frac{Q}{U \square T_{L M}}
$$

Eqs. (6) and (7) were presented separately to emphasize the existence of thermodynamic restrictions and $\Delta \mathrm{T}_{\min }$. However, they can be combined, as in Eq. (11).

$$
\begin{aligned}
& {\left[T h _ { \text { in } } L _ { k } \square \left[T c_{\text {out }} L_{k} \mathrm{t} \Delta \mathrm{T}_{\text {min }}\right.\right.} \\
& {\left[T h _ { \text { out } } [ ] _ { k } \square \left[c_{\text {in }} L_{k} \mathrm{t} \Delta \mathrm{T}_{\text {min }}\right.\right.} \\
& \mathrm{k} \quad 1, \ldots, \text { number of equipment }
\end{aligned}
$$

Genetic operators used in this stage are the same used in the previous section, however, adapted to the new problem.

\section{CASE STUDY}

To test the methodology developed, a case was studied. The problem was presented in Ahmad (1985) and has 10 process streams (6 hot and 4 cold), a hot utility stream (steam) and a cold utility stream (cold water).

The value of $\mathrm{DT}_{\text {min }}$ proposed by Ahmad (1985) was $10^{\circ} \mathrm{C}$, and this value was not optimized previously. Streams data and cost equation parameters are presented in Tab. 1. Eq. (12) presents the equation, where $C$ is in $\$$ and $A$ in $\mathrm{m}^{2}$.

$$
\text { C 60ロA }
$$

The value of $\Delta \mathrm{T}_{\min }$ was optimized and Fig. 1 shows capital, energy and global cost functions. It was necessary 57 generations to find the optimum value of $24^{\circ} \mathrm{C}$ for $\Delta \mathrm{T}_{\min }$. The population was set to 50 individuals and the mutation rate was $40 \%$. The heat exchangers network was synthesized using the same $24^{\circ} \mathrm{C}$ for $\Delta \mathrm{T}_{\min }$. The problem was divided into two subproblems, below and above the pinch, and maximum energy recovery was found by using Pinch Analysis. In this case, the heat exchanger synthesized has the minimum energy and capital costs. The heat exchangers network synthesized is presented in Fig. 2. 
Table 1. Streams data and cost parameters.

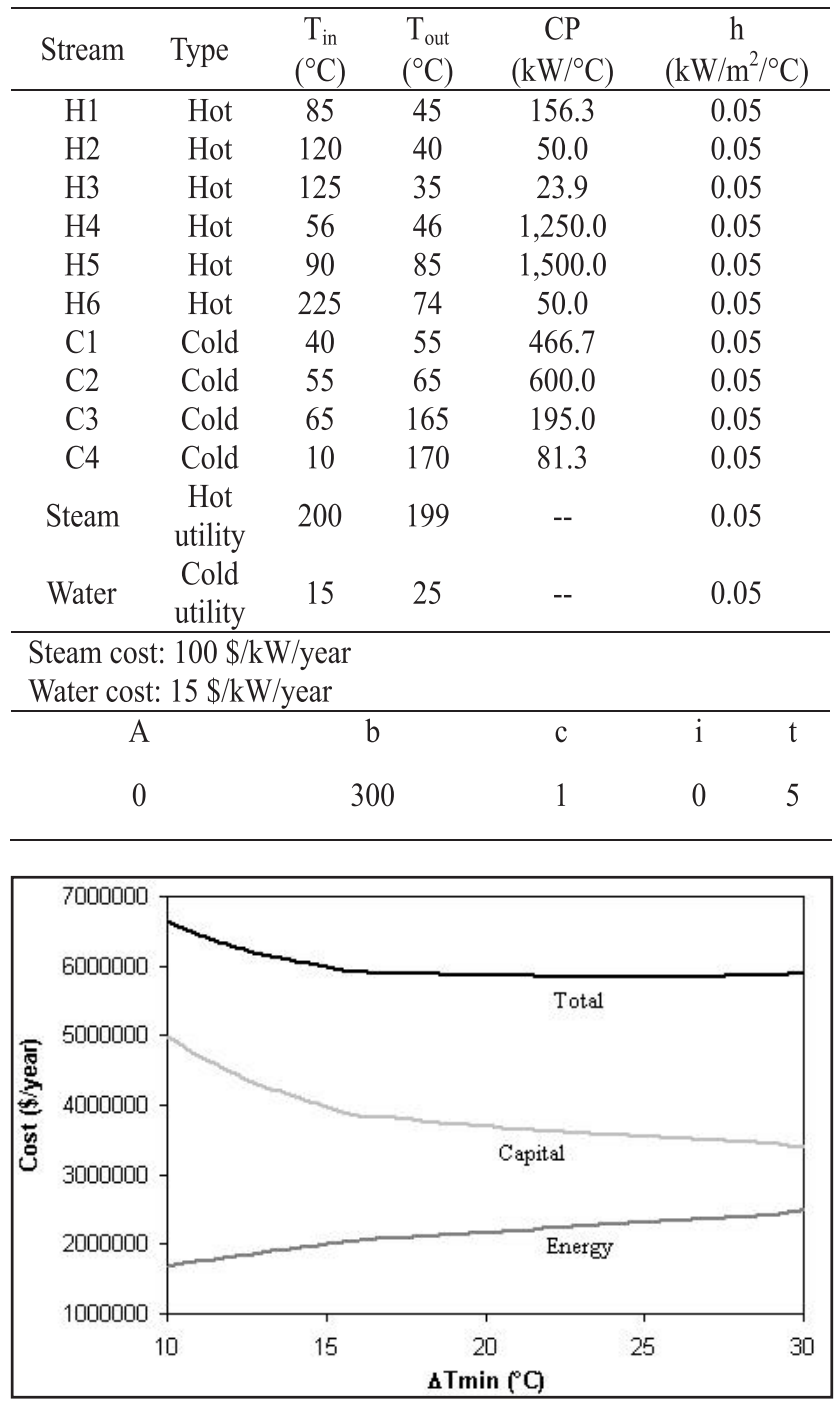

Figure 1. $\Delta \mathrm{T}_{\min }$ Optimization

Table 2 presents results comparison. It was necessary 8 generations to find the minimum value of the objective function, and the minimum cost obtained is $5.673 \mathrm{M} \$ /$ year. The heat transfer area is $56,600.56 \mathrm{~m}^{2}$. The population was set to 20 individuals and the mutation rate was between $10 \%-80 \%$. Cost data are the same used in previous section. Relaxation value for $\Delta \mathrm{T}_{\min }$ was 0.71 .

\section{CONCLUSIONS}

In most papers published in the literature, the $\Delta \mathrm{T}_{\text {min }}$ optimization step is neglected.

In general, an arbitrary value is used to the heat exchanger synthesis. Nevertheless, if an inadequate value is chosen, bad solutions from the point of view of utilities consumption and capital cost will be achieved.
The proposed methodology, using Genetic Algorithms, is efficient to find optimal $\Delta \mathrm{T}_{\text {min }}$ values as well as optimal heat exchanger networks configurations, being easy to use.

The utilization of algorithms developed based on the application of Pinch Analysis to identify the pinch point and the minimum energy demand and the minimum number of equipment allows the user to find fast and automatically the best possible alternatives. Besides, these algorithms are versatile, being adaptable to several kinds of problems by modifying or including the set of hypothesis and considerations.

To the case studied, the value used in Ahmad (1985) to the $\Delta \mathrm{T}_{\min }$ is very different than the optimized value. In the case studied, the value proposed by Ahmad $(1985)$ was $10^{\circ} \mathrm{C}$. Using the procedure developed for the $\Delta \mathrm{T}_{\min }$ optimization, the value found was $24^{\circ} \mathrm{C}$. For the $\Delta \mathrm{T}_{\text {min }}$ proposed in literature, Ahmad (1985), the values for the HEN are very different, as can be seen in Tab. 4 . The minimum global cost is achieved for $\Delta \mathrm{T}_{\text {min }}$ of $24^{\circ} \mathrm{C}$. Although the energy cost is grater than the presented in the literature, the capital cost is minor. Because of that, the global annual cost is minimum, as compared to literature.

Finally, one can conclude that the proposed systematic is efficient in the first step of the design, $\Delta \mathrm{T}_{\min }$ optimization, as well as in the optimal heat exchangers network synthesis.

Table 2. Results comparison

\begin{tabular}{ccc}
\hline & $\begin{array}{c}\text { Ahmad } \\
(1985)\end{array}$ & Present paper \\
\hline Hot utility $(\mathrm{kW})$ & 15,400 & $20,529.3$ \\
Cold utility $(\mathrm{kW})$ & 9,796 & $14,923.8$ \\
Total area $\left(\mathrm{m}^{2}\right)$ & $-{ }^{*}$ & $56,600.56$ \\
Energy cost $(\$$ year $)$ & $1,686,940$ & $2,276,787$ \\
Capital cost $\$$ /year) & $5,387,060$ & $3,396,034$ \\
Total cost $\$$ /year) & $7,074,000$ & $5,672,821$ \\
\hline
\end{tabular}

$\left.{ }^{*}\right)$ Not supplied in the reference

\section{REFERENCES}

AHMAD, S., 1985, Heat exchanger networks: cost tradeoffs in energy and capital, Doctoral Thesis, Faculty of Technology, University of Manchester Institute of Science and Technology, Manchester, UK.

Castell, C. M. L., Lakshmanan, R., Skilling, J. M., 1998, Optimization of Process Plant Layout 


\section{TECNOLOGIA/TECHNOLOGY}

Using Genetic Algorithm. Computers and Chemical Engineering, Vol. 22, pp. S993 - S996.

Floudas, C. A., Ciric A. R., and Grossmann, I. E., 1986, Automatic Synthesis of Optimum Heat Exchanger Network Configurations, AIChE Journal, Vol. 32, No. 2, pp. 276 - 290.

Hugget, A.; Sebastian, P. and Nadeau, J. P., 1999, Global Optimization of a Dryer by Using Neural Networks and Genetic Algorithms. AIChE Journal, Vol. 45, No. 6, pp. $1227-1238$.

Linnhoff, B., 1994, Use Pinch Analysis to knock down Capital Cost and Emissions, Chemical Engineering Progress, Aug., pp. 32-57.

Linnhoff, B., 1993, Pinch Analysis: A stateof-art Overview, Transactions of the IChemE, Vol. 71, Part A, pp. 503-522.

Linnhoff, B., Hindmarsh, E., 1983, The Pinch Design Method for Heat Exchanger Networks. Computers and Chemical Engineering, Vol. 38, No. 5, pp. 745-763.

Linnhoff, B., Towsend, D. W., Boland, D., Hewitt, G. F., Thomas, B. E. A., Guy, A. R., Marsland, R. H., A, 1982, User Guide on Process Integration for the Efficient Use of Energy, The Institute Of Chemical Engineers, U.K.

Nougués, J. M., Grau, M. D., Puigjaner, L. 2002, Parameter Estimation with Genetic Algorithm in Control of Fed-Batch Reactors. Chemical Engineering and Processing, Vol. 41, pp. 303-309.

Papoulias, S. A., Grossmann, I. E. A., 1983, Structural Optimization Approach in Process Synthesis - II: Heat Recovery Networks, Computers and Chemical Engineering, Vol. 7, No. 6, pp. 707-721.

Ravagnani, M. A. S. S., Silva, A. P., Andrade, A. L., 2003, Detailed Equipment Design in Heat Exchanger Networks Synthesis and Optimization, Applied Thermal Analysis, Vol. 23, pp. 141- 51.

Ravagnani, M. A. S. S., Silva, A. P., Arroyo, P. A., Constantino, A. A., 2005, Heat Exchanger Network Synthesis and Optimization Using Genetic Algorithm, Applied Thermal Analysis, Vol. 25, pp. 1003-1017.

Stephan, E. A. and Chase, G. G., 2003, Use of Genetic Algorithms as an Aid in Modeling Deep Bed Filtration. Computers and Chemical Engineering, Vol. 27, pp. 281-292.

Wang, K., Qian, Y., Yuan, Y., 1998,
Synthesis and Optimization of Heat Integrated Distillation Systems Using an Improved Genetic Algorithm. Computers and Chemical Engineering, Vol. 23, pp. 125-36.

Yuen, C. C.; Aatmeeyata; Gupta, S. K. et al., 2000, Multi-objective optimization of membrane separation modules using genetic algorithm. Journal of Membrane Science, Vol. 176, pp. 177-196.

\section{APPENDIX}

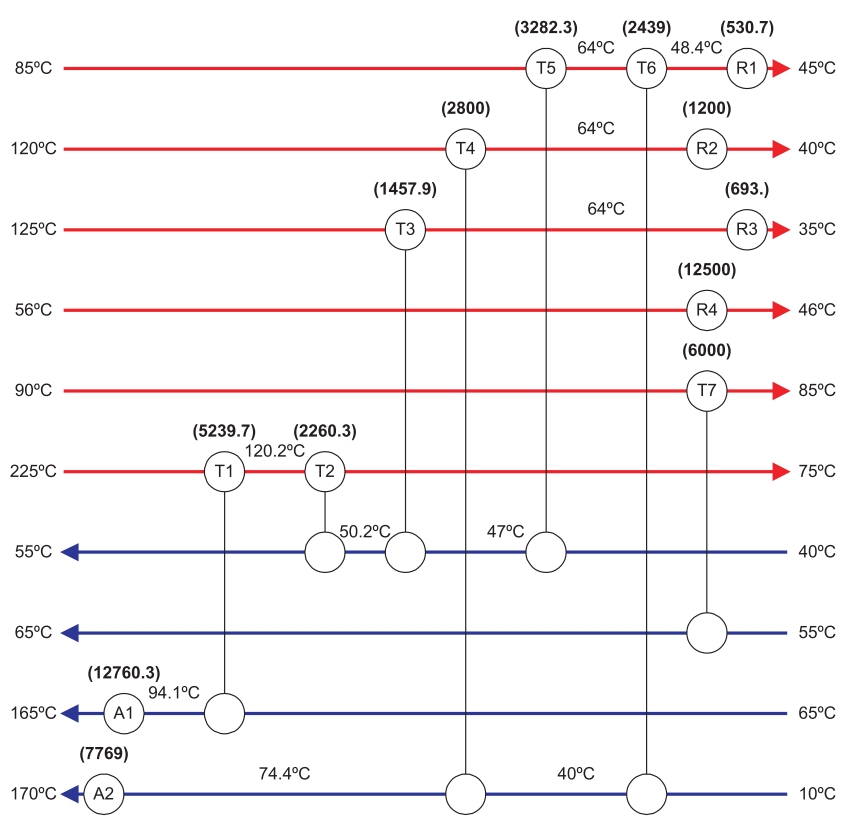

Figure 2. Final heat exchanger network. 